\title{
Strength of Joints with "Hi-Lok" Fasteners in Aircraft Safety Considerations
}

\author{
Mariusz Kłonica ${ }^{1 *}$, Radosław Bielawski² \\ 1 Lublin University of Technology, Faculty of Mechanical Engineering, Department of Production Engineering, \\ 36 Nadbystrzycka Street, 20-618 Lublin \\ 2 War Studies University, Faculty of National Security, Al. gen. Antoniego Chruściela "Montera” 103, \\ 00-910 Warszawa \\ * Corresponding author's e-mail:m.klonica@pollub.pl
}

\begin{abstract}
This paper reports on the results of strength tests of single-lap joints used in the aerospace industry with "Hi-Lok" fastener. The samples subjected to testing were made of EN-AW 2024 aluminium alloy and carbon composite. A part of the samples was additionally sealed with the use of Naftoseal MC-780 Class C sealant. The application of the MC-780 Class C sealant boosts the strength of a single lap joint of EN-AW 2024 T3 Al alloy and carbon composite. The strength test results were complemented with the analysis of selected 2D and 3D surface roughness parameters, and isometric images of the analysed surfaces. Additional information on the specimen surface quality was provided with photographic images taken with Keyence VHX-5000 microscope at x300 magnification. In the conclusion section of this paper, the study is summarised and its key findings are listed.
\end{abstract}

Keywords: aluminium alloy, carbon composite, surface layer, surface roughness

\section{INTRODUCTION}

Material joining, especially with respect to producing assembly joints, is a vital and extensive issue in production engineering. Homogeneous and heterogeneous materials are joined for various purposes and in virtually all areas of life; their importance in aerospace applications is no exception $[4,7]$.

It is already at the designing stage that the engineer/constructor is faced with a critical decision: the selection of the structural material joining method and the selection of the appropriate fastener. Ever-increasing requirements force the designer to focus on improvement and development of material joining technology in order to account for the novelty materials, aluminium alloys and composites [1]. As a result, new concepts of design solutions and innovative joining techniques are regularly tested and introduced, particularly considering joint assemblies of homogeneous substrates, such as aluminium and composites. This latter combination of structural materials is increasingly popular in the aerospace industry. In addition to the strength of the implemented fastener, other aspects must be necessarily considered in the decision-making process, i.e. the simplicity of installation or economic considerations $[8,9]$. One of the effective methods of assembly and joining of modern structural materials that has been developed in recent years is the "Hi-Lok" fastener. A rather simple design ensures ease of assembly and acceptable weight while offering relatively high strength, which is why these fasteners are extensively used in the production process, especially in the aircraft industry.

In certain industries, such as in the aerospace industry, hermetically sealed assemblies are required of the finished product. What is more, it is of utmost importance that the safety of such assemblies is maintained throughout their 
lifecycle. In order to decrease the risk of joint failure, prior to sealing, the substrates must essentially undergo appropriate surface treatment. One of the most commonly applied surface treatments are: mechanical methods (milling, grinding, burnishing [10], brushing [6]), chemical, electrochemical, or ozone treatment to name a few. As a rule, these technologies are designed to develop the surfaces in the geometric sense $[2,3,5,11]$.

The test specimens were prepared by assembling EN-AW 2024 T3 Al alloy and carbon composite with "Hi-Lok" fasteners and applying the Naftoseal MC-780 Class C aircraft sealant. The Al alloy employed in the study is characterised by high copper content and shows good fatigue strength. Its exceptionally low corrosion resistance limits the scope of its applications to structures where there is no risk of oxidation. Moreover, it is implemented in components where good specific strength is required. EN-AW 2024 T3 Al alloy is widely used, among others, in the aircraft industry.

In part, specimens were made with Naftoseal MC-780 Class C sealant. It is a two-component sealant with reduced density for fuel tank or hermetic fuselage seal applications. It was developed for interfay surface sealing and wet riveting of fuselage components. Its applicability in aerospace applications results from its resistance to aviation fuel and other chemical products used in the aircraft industry, and the fact that it can be used on a range of aviation substrate materials, e.g. aluminium alloys, stainless steel, titanium alloys or composites. MC-780 Class C sealant combines high strength with low viscosity. Moreover, the latter feature is highly beneficial from the viewpoint of mixing and application, which can be performed by injection gun or by means of roller coating.

\section{EXPERIMENTAL PROCEDURE}

HL20PB-5 "Hi-Lok" fasteners, were installed, their length was adjusted to the overall thickness of the single-lap joint. The fastener assembly consisted of the dowel with a protruding tension head of cadmium-plated galvanic steel and the HL86PB-5 collar.

The single-lap specimens were assembled of $100 \mathrm{~mm} \times 50 \mathrm{~mm}$ sheets of $1.6 \mathrm{~mm}$ thick ENAW $2024 \mathrm{Al}$ alloy and $1.4 \mathrm{~mm}$ thick carbon composite. Having subjected the specimen edges to deburring operation, the specimens were holes were produced in the substrates; the hole dimensions are given in Figure 1. Prior to joining, the overlapping sample surface was cleaned with acetone. Table 1 lists the produced singlelap joint assembly variants of aircraft substrates and sealant.

Specimens T2, T4 and T6 were assembled with the application of sealant; the procedure was as follows. The substrates were subjected to degreasing at the sealant application site. The sealant was applied by hand, and the joint assemblies were subsequently fastened with spring clips so that the sealant is fully polymerised, as per the manufacturer's instructions. Once the sealant was fully polymerised, the specimens were placed in clamps in order to provide stability during installation of the "Hi-Lok" fittings.

After assembly the specimens were subjected to quality control, which involved checking: the position of fasteners, the overlap length, the tightness of fit between the Hi-Lok pin and collar, the number of threads protruding from under the collar, the sealant flash. Once the assembly and the quality control procedures were completed, the specimens were subjected to strength tests on the Zwick/Roell Z150 tensile and compression testing machine shown in Figure 2. The strength tests

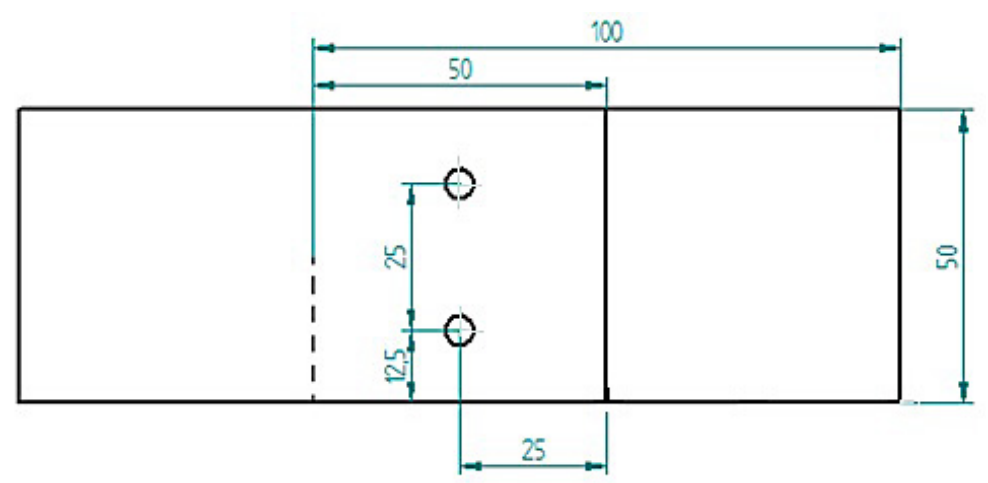

Fig. 1. The schematics of the tested joint with "Hi-Lok" fastener 
Table 1. Joint sample variants

\begin{tabular}{|c|l|}
\hline Variant & \multicolumn{1}{|c|}{ Joint assembly } \\
\hline T1 & Al EN-AW 2024 alloy - Al EN-AW 2024 alloy \\
\hline T2 & Al EN-AW 2024 alloy - MC-780 Class C sealant - Al EN-AW 2024 alloy \\
\hline T3 & Al EN-AW 2024 alloy - Carbon composite \\
\hline T4 & Al EN-AW 2024 alloy - MC-780 Class C sealant - Carbon composite \\
\hline T5 & Carbon composite - Carbon composite \\
\hline T6 & Carbon composite - MC-780 Class C sealant - Carbon composite \\
\hline
\end{tabular}

of the single-lap joints were carried out in accordance with DIN EN 1465. The traverse speed during the test was $2 \mathrm{~mm} / \mathrm{min}$, hence the conducted tests were static.

The selected surface roughness parameters measurements (2D and 3D) were carried out on a device for measuring contour, roughness and 3D topography T8000 RC-120-400 Hommel-Etamic roughness and contour measurement system equipped with a $2 \mu \mathrm{m} / 90^{\circ}$ stylus tip. The analysis of the obtained results was performed by means of TURBO WAVE software.

The tests and measurements also involved the application of Keyence VHX-5000 microscope to produce images the EN-AW $2024 \mathrm{~T} 3 \mathrm{Al}$ alloy and carbon composite specimen surface. a)

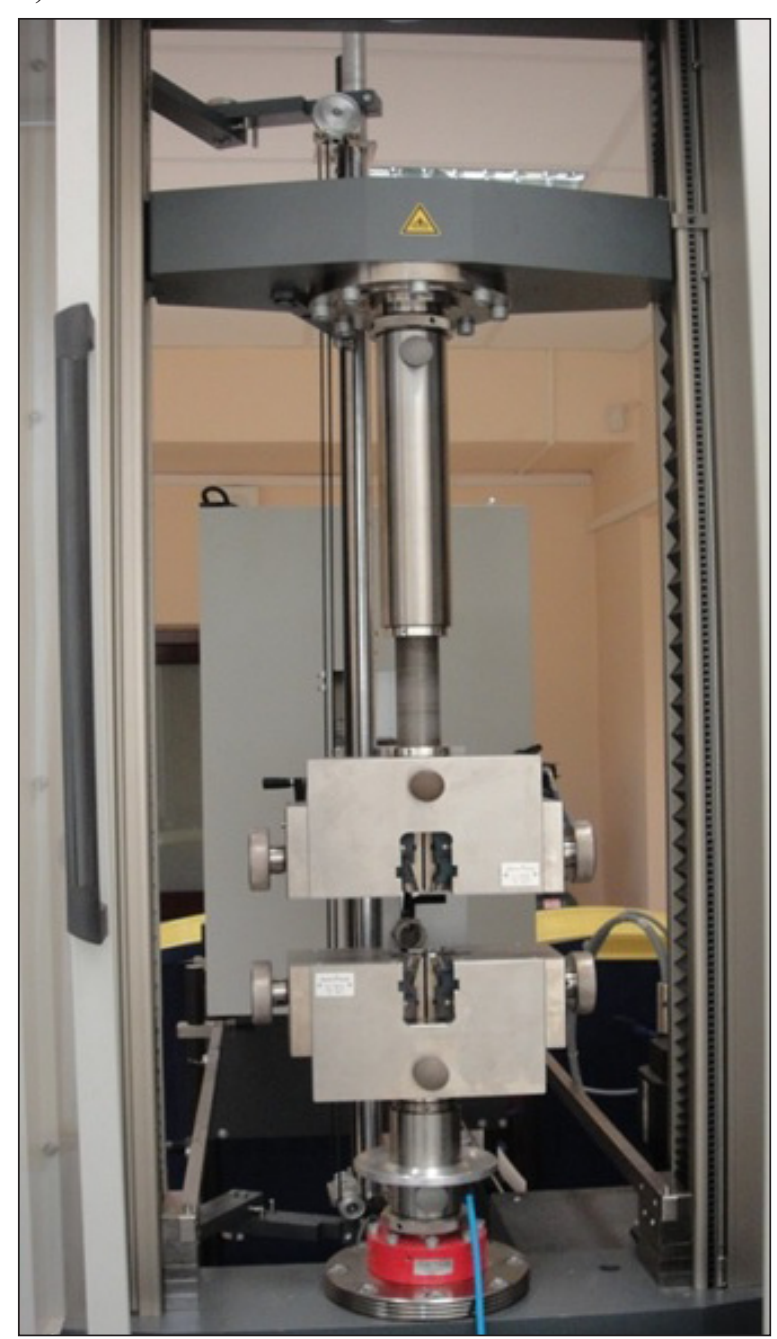

b)

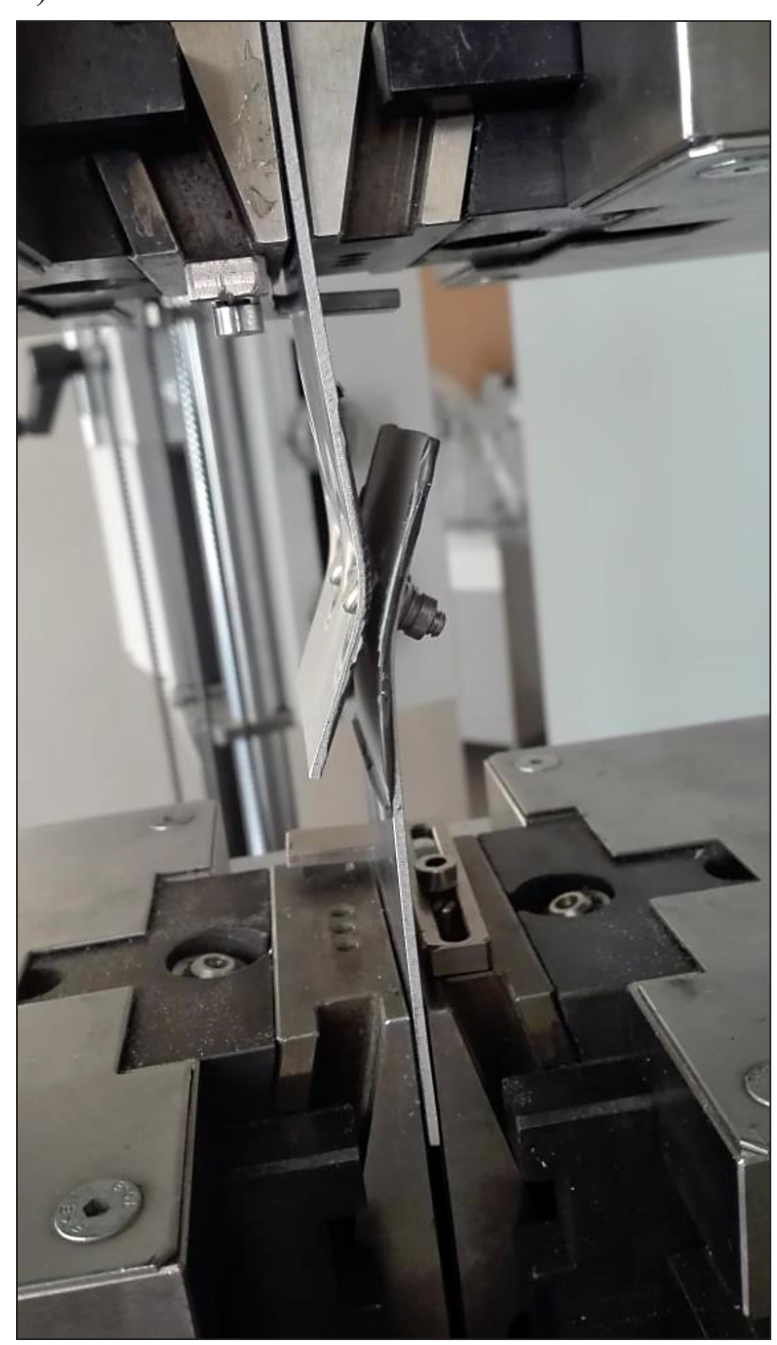

Fig. 2. The Zwick/Roell Z150 testing machine employed in tests (a), sample (b) 


\section{RESULTS AND DISCUSSION}

Table 2 presents the results of topography tests of the EN-AW 2024 T3 Al alloy surface.

The performed tests showed that the surface of specimens used in the study exhibited beneficial conditions in the geometric sense, which is a prerequisite for conducting effective hermetic sealing of the component.

Table 3 shows the results of the topography analysis of the carbon composite surface used in the study.

The carbon composite substrate, similarly to the EN-AW 2024 T3 Al alloy, was characterised by an adequate degree of surface development. Therefore, no machining is required to further treat the surface for adhesive technologies - such as joint sealing.

The surface quality of modern aircraft materials tested here is presented in Table 4, which shows isometric and photographic images of their surface obtained from the Keyence VHX-5000 microscope at magnification 300x.
The results of selected $2 \mathrm{D}$ surface roughness parameter measurements for both the EN-AW 2024 T3 Al alloy and the carbon composite are given in Table 5 . The surface roughness parameters were tested in at least five measurements, the mean values of whose are presented in the table.

The following surface roughness parameters were investigated: $\mathrm{Ra}$ - arithmetical mean deviation of the profile, $\mathrm{Rc}$ - mean height of the profile elements, $\mathrm{Rp}$ - maximum profile peak height, $\mathrm{Rq}-$ root mean square deviation of the profile, $\mathrm{Rt}$ - total height of the profile, $\mathrm{Rv}$ - maximum valley depth of the profile, $\mathrm{Rz}$ - maximum height of the profile. Based on the analyses, it was found that it was the carbon composite that exhibited much higher values of surface roughness compared to the corresponding EN-AW 2024 T3 Al alloy.

The results of selected 3D surface roughness parameter measurements for both EN-AW 2024 T3 Al alloy and carbon composite are presented in Table 6.

Table 2. Topography of EN-AW 2024 T3 Al alloy

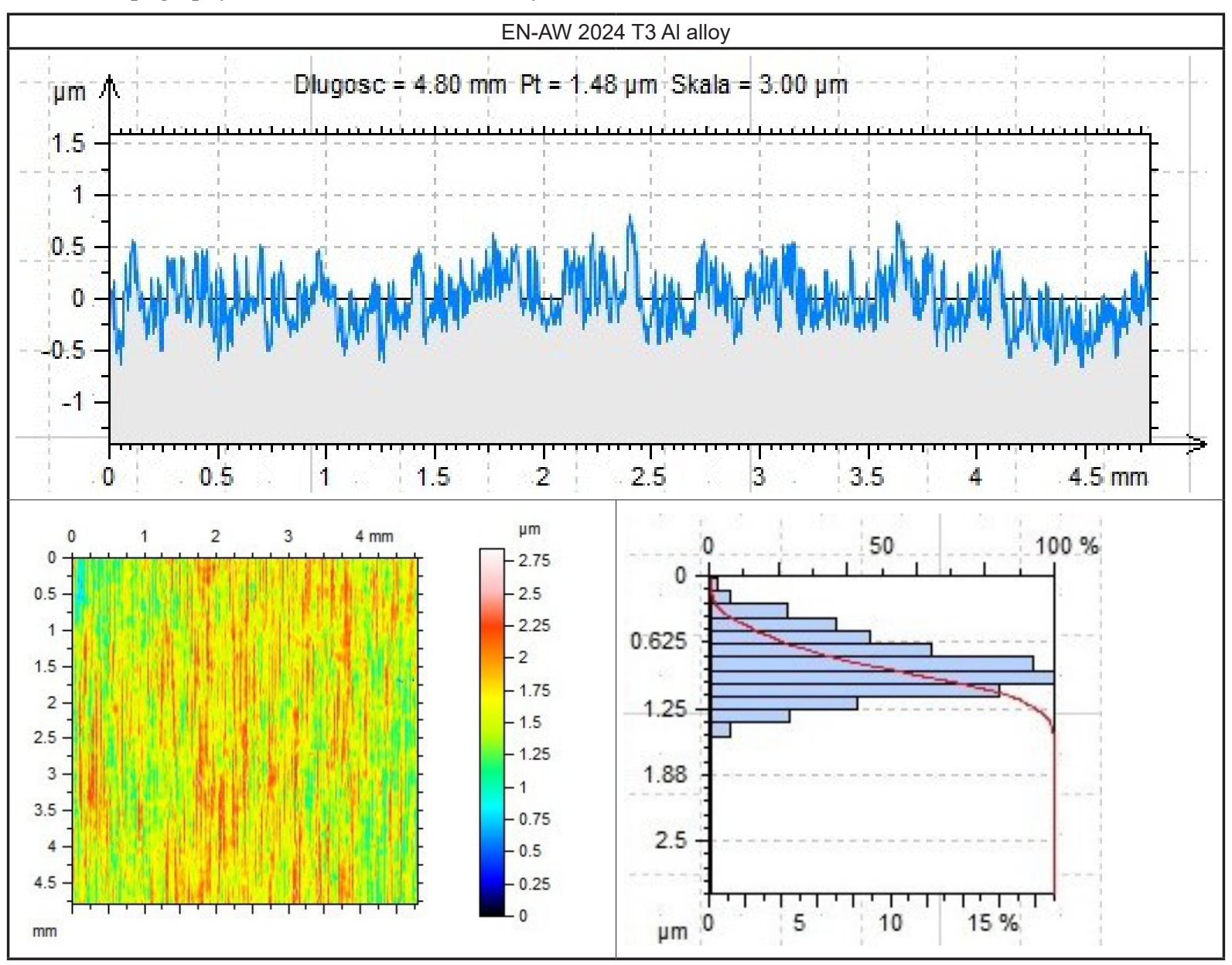


Table 3. Carbon composite surface topography

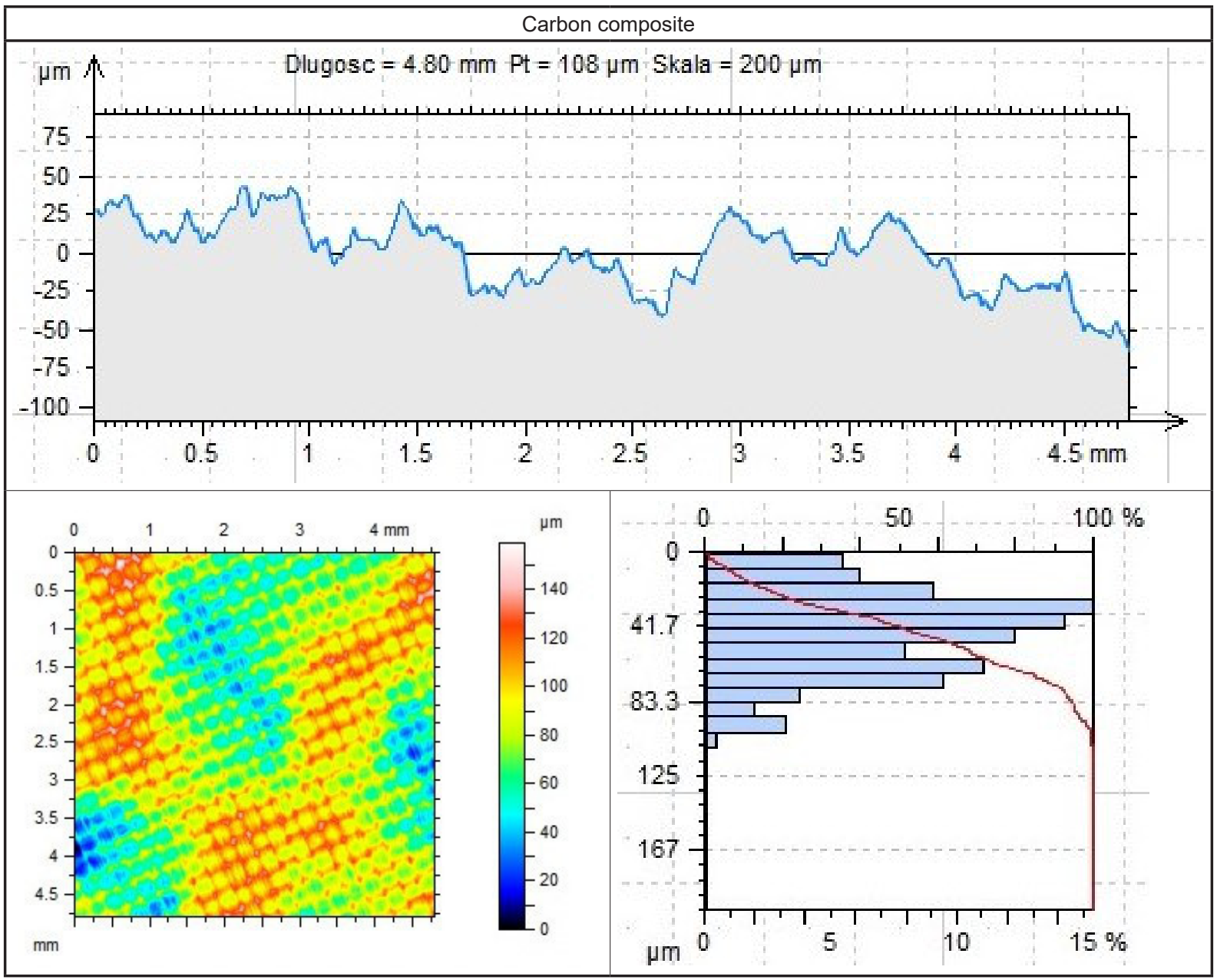

As in the case with the 2D parameters, 3D parameters obtained for carbon substrate showed higher numerical values. The following $3 \mathrm{D}$ roughness parameters were analyzed: $\mathrm{Sa}$ - arithmetic mean height of the 3D profile, $\mathrm{Sp}$ - maximum peak height of the 3D profile, $\mathrm{Sq}$ - root mean square roughness of the $3 \mathrm{D}$ profile, $\mathrm{Sv}-$ maximum valley depth of the 3D profile, $\mathrm{Sz}-$ maximum height of the 3D profile.

Figure 3 presents the effect of the joint assembly variant on the force value obtained in strength tests on the Zwick/Roell Z150 machine.

The tests performed in the study clearly indicate that it was the joint assembly variant $\mathrm{T} 2$ that developed the highest strength among the tested specimens (EN-AW 2024 T3 aluminium alloy + MC-780 class $C$ sealant). The lowest value was recorded in hybrid joint assemblies - T3; however, it was further shown that by the application of sealant (T4 joint variant) the force required to break the hybrid joint is notably increased. What may be inferred is that the application of the sealant, in addition to the somewhat standard outcome, i.e. hermetic sealing, the sealant contributes to the increase in the strength of the joint assembly, both of which are crucial in the aerospace industry. Finally, the standard deviation values for all specimen variants were exceptionally low, thus confirming low scatter of test results.

\section{CONCLUSIONS}

The tests conducted as part of this study have allowed us to formulate the following general conclusions:

The test results of selected 2D and 3D surface and area roughness parameters for both the EN-AW 2024 T3 Al alloy and the carbon composite showed an appropriate degree of surface development in the geometric sense, which is a prerequisite for effective hermetic sealing.

The produced isometric and magnified images of the specimen surface confirmed the homogeneity of the specimens under test. 
Table 4. EN-AW $2024 \mathrm{~T} 3 \mathrm{Al}$ alloy and carbon composite surface imagery

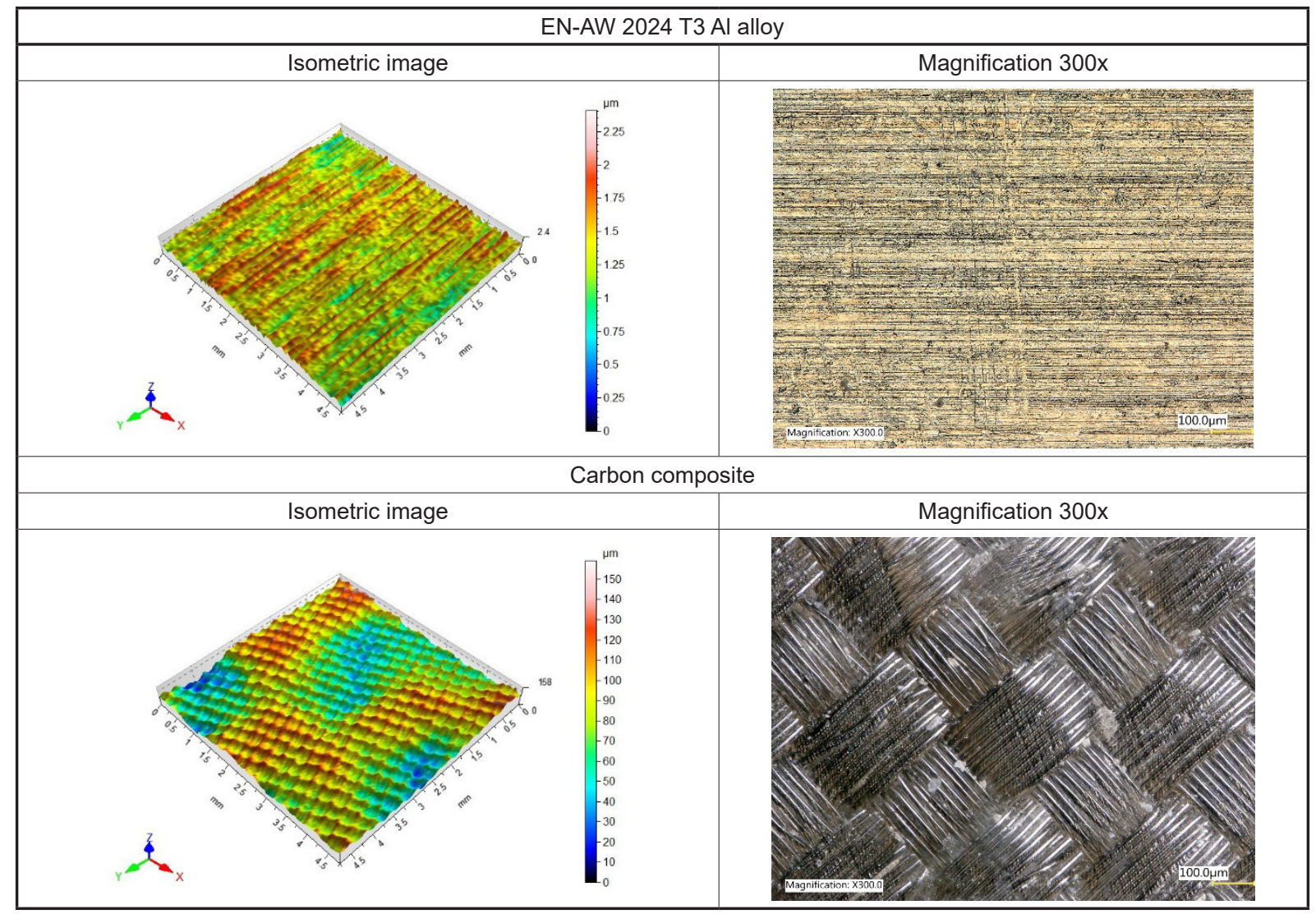

Table 5. Selected 2D surface roughness measurement results

\begin{tabular}{|l|l|l|}
\hline $\begin{array}{l}\text { 2D surface roughness } \\
\text { parameters }\end{array}$ & $\begin{array}{l}\text { EN-AW 2024 T3 } \\
\text { Al alloy }\end{array}$ & $\begin{array}{l}\text { Carbon } \\
\text { composite }\end{array}$ \\
\hline Rp $[\mu \mathrm{m}]$ & 0.59 & 17.9 \\
\hline $\operatorname{Rv}[\mu \mathrm{m}]$ & 0.49 & 17.3 \\
\hline $\operatorname{Rz}[\mu \mathrm{m}]$ & 1.09 & 35.2 \\
\hline $\operatorname{Rc}[\mu \mathrm{m}]$ & 0.50 & 23.8 \\
\hline Rt $[\mu \mathrm{m}]$ & 1.30 & 42.4 \\
\hline $\operatorname{Ra}[\mu \mathrm{m}]$ & 0.19 & 7.26 \\
\hline $\operatorname{Rq}[\mu \mathrm{m}]$ & 0.23 & 8.72 \\
\hline
\end{tabular}

Table 6. Selected 3D surface roughness measurement results

\begin{tabular}{|l|l|l|}
\hline $\begin{array}{l}\text { 3D surface roughness } \\
\text { parameter }\end{array}$ & $\begin{array}{l}\text { EN-AW 2024 T3 } \\
\text { Al alloy }\end{array}$ & $\begin{array}{l}\text { Carbon } \\
\text { composite }\end{array}$ \\
\hline Sq $[\mu \mathrm{m}]$ & 0.267 & 23.3 \\
\hline Sp $[\mu \mathrm{m}]$ & 1.02 & 76.0 \\
\hline Sv $[\mu \mathrm{m}]$ & 1.38 & 83.1 \\
\hline Sz $[\mu \mathrm{m}]$ & 2.41 & 159 \\
\hline Sa $[\mu \mathrm{m}]$ & 0.215 & 19.2 \\
\hline
\end{tabular}

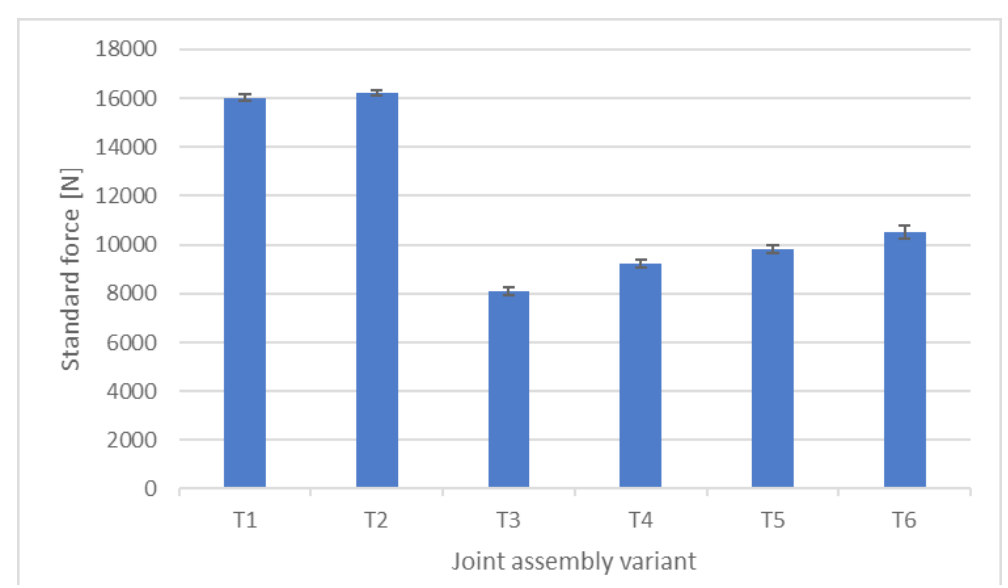

Fig. 3. The impact of joint type preparation on the obtained force value 
The highest values of the destructive force of the single lap joint formed with the "Hi-Lok" fastener was recorded for the T2 joint assembly variant, and amounted to $16.1 \mathrm{kN}$.

The application of the MC-780 Class C sealant boosts the strength of a single lap joint of EN-AW 2024 T3 Al alloy and carbon composite.

\section{REFERENCES}

1. Bielawski R., Rządkowski W., Augustyn S., Pyrzanowski P. Nowoczesne materiały stosowane w konstrukcjach lotniczych - wybrane problemy oraz kierunki rozwoju, Mechanika 87(3/15), DOI: 10.7862/rm.2015.20.

2. Kłonica M. Comparative analysis of effect of thermal shock on adhesive joint strength. Advances in Science and Technology Research Journal, 10(32), 2016, 263-268.

3. Kłonica M. Impact of Thermal Fatigue on Young's Modulus of Epoxy Adhesives. Advances in Science and Technology Research Journal, 9(28), 2015, 103-106.

4. Kubit A., Trzepiecinski T., Swiech L., Faes K., Slota J. Experimental and Numerical Investigations of Thin-Walled Stringer-Stiffened Panels Welded with RFSSW Technology under Uniaxial Compression. Materials,12(11) 2019, 1785.
5. Kuczmaszewski J. Fundamentals of metal-metal adhesive joint design. Politechnika Lubelska. Lublin, 2006.

6. Matuszak J., Zaleski K. Analysis of deburring effectiveness and surface layer properties around edges of workpieces made of 7075 aluminium alloy. Aircraft Engineering and Aerospace Technology, 90(3), 2018, 515-523.

7. Samborski S., Gliszczynski A., Rzeczkowski J., Wiacek N. Mode I Interlaminar Fracture of Glass/ Epoxy Unidirectional Laminates. Part I: Experimental Studies. Materials, 12(10), 2019, 1607.

8. Skoczylas J., Samborski S., Kłonica M. Experimental Study on Static and Dynamic Fracture Toughness of Cured Epoxy Resins. Advances in Science and Technology Research Journal, 13(1), 2019, 122-127.

9. Szala M., Hejwowski T. Cavitation Erosion Resistance and Wear Mechanism Model of FlameSprayed Al2O3-40\%TiO2/NiMoAl Cermet Coatings. Coatings, 8(7), 2018, 254; https://doi. org/10.3390/coatings8070254.

10. Zaleski K., Skoczylas A., Brzozowska M. The Effect of The Conditions of Shot Peening The Inconel 718 Nickel Alloy on The Geometrical Structure of The Surface. Advances in Science and Technology Research Journal, 11(2), 2017, 205-211.

11. Żenkiewicz M. Comparative study on the surface free energy of a solid calculated by different methods. Polymer Testing, 26, 2007, 14-19. 